\title{
Risperidone-induced reversible neutropenia
}

This article was published in the following Dove Press journal:

Neuropsychiatric Disease and Treatment

25 July 2017

Number of times this article has been viewed

\author{
Vasanth Kattalai Kailasam' \\ Victoria Chima ${ }^{2, *}$ \\ Uchechukwu Nnamdi ${ }^{3, *}$ \\ Kavita Sharma ${ }^{4, *}$ \\ Kairav Shah ${ }^{5}$ \\ 'College of Medicine, University of \\ Illinois, Chicago, IL, USA; ${ }^{2}$ Mount Sinai \\ Beth Israel Medical Center, New York, \\ NY, USA; ${ }^{3}$ Albert Einstein College \\ of Medicine/Montefiore Medical \\ Center, Bronx, NY, USA; ${ }^{4} \mathrm{Harlem}$ \\ Hospital Center, New York, NY, USA; \\ ${ }^{5}$ Department of Psychiatry \& \\ Behavioral Sciences, The University \\ of Texas McGovern Medical School, \\ Houston, TX, USA \\ *These authors contributed equally \\ to this work
}

\begin{abstract}
This case report presents a 44-year-old man with a history of schizophrenia who developed neutropenia on risperidone therapy. The patient's laboratory reports showed a gradual decline of leukocytes and neutrophils after resolution and rechallenging. This was reversed with the discontinuation of risperidone and by switching to olanzapine. In this case report, we also discuss the updated evidence base for management of risperidone-induced neutropenia.
\end{abstract}

Keywords: risperidone, antipsychotics, neutropenia, blood dyscrasias

\section{Introduction}

Hematologic abnormalities are frequent and may be life-threatening complications of antipsychotics. ${ }^{1}$ Neutropenia, defined as a consistently low absolute neutrophil count ( $\mathrm{ANC} ;<1,500 / \mathrm{uL}$ ), can be due to reduced production or increased peripheral destruction. ${ }^{2}$ There is a class warning stating that antipsychotics may cause blood dyscrasias, which include leukopenia, neutropenia, and agranulocytosis. Neutropenia is a rare side effect of risperidone. Clozapine requires regular monitoring of white blood cells (WBCs)/ANC with computed based registry. Risperidone, olanzapine, and other antipsychotics do not have the same monitoring regulatory process as clozapine. We report a case of leukopenia and neutropenia occurring during treatment with risperidone, reversible with discontinuation of the medication, reoccurrence during rechallenge, and resolution after switching to olanzapine.

\section{Case}

A 44-year-old Hispanic man was admitted to our Comprehensive Psychiatric Emergency Program (CPEP) with complaints of auditory hallucinations and suicidal ideation. The patient had a history of schizophrenia, multiple suicide attempts and self-injurious behavior, alcohol use disorder, and cocaine use disorder. His medical history was significant for Hepatitis B and bronchial asthma. He reported taking risperidone for schizophrenia for 10 days, but compliance was questionable. He reported auditory hallucinations, depressed mood, hopelessness, helplessness, and both poor sleep and appetite. No abnormalities were detected in baseline laboratory values. WBC count was $5,600 / \mu \mathrm{L}$, ANC $3,600 / \mu \mathrm{L}$, lymphocytes $1,200 / \mu \mathrm{L}$, monocytes $700 / \mu \mathrm{L}$, eosinophils $0.0 / \mu \mathrm{L}$, and basophils $0.0 / \mu \mathrm{L}$. Urine toxicology was positive for cocaine. Patient was started on risperidone $1 \mathrm{mg}$ po twice daily for psychosis and escitalopram $20 \mathrm{mg}$ daily for depression. On the second day, routine laboratory tests showed a decrease in both his WBCs and ANC. WBCs decreased to 3,800/ $\mu \mathrm{L}$ and neutrophils to $0.0 / \mu \mathrm{L}$; lymphocytes were $700 / \mu \mathrm{L}$, monocytes $90 / \mu \mathrm{L}$, eosinophils $10 / \mu \mathrm{L}$, and basophils $0.0 / \mu \mathrm{L}$. The following day, the values of $\mathrm{WBC}$ continued to drop up to $1,100 / \mu \mathrm{L}$, and neutrophils to $0.0 / \mu \mathrm{L}$, lymphocytes were $220 / \mu \mathrm{L}$, monocytes $400 / \mu \mathrm{L}$, eosinophils $0.0 / \mu \mathrm{L}$, and basophils $0.0 / \mu \mathrm{L}$. The patient spiked a fever on his third day
Correspondence: Kairav Shah Department of Psychiatry \& Behavioral Sciences, The University of Texas McGovern Medical School 194I East Road, Houston, TX 77054, USA Email kairav2305@gmail.com
Neuropsychiatric Disease and Treatment 2017:13 1975-1977

1975

Dovepress if in 0

http://dx.doi.org/10.2147/NDT.S141472 
in CPEP. The patient was transferred to the Internal Medicine ward for further management. Imaging studies and culture reports were not suggestive of any infective foci. Meanwhile, the patient was receiving risperidone $1 \mathrm{mg}$ po twice daily on the Internal Medicine ward. Both Infectious Disease and Hematology/Oncology consultation teams gave an impression of medication-induced neutropenic fever and suggested discontinuation of risperidone. After discontinuation of risperidone, neutrophil count improved. On the 7 th day after discontinuing risperidone, the count reached the baseline value. WBCs increased to $5,200 / \mu \mathrm{L}$ and neutrophils to $1,800 / \mu \mathrm{L}(35.2 \%)$. The patient was unwilling to be switched to another antipsychotic medication and left the hospital against medical advice. He presented to CPEP again after one month, with suicidal ideation and noncompliance with medication. He was rechallenged with risperidone because of patient preference. His WBC count dropped from a baseline value of $4,500 \mu \mathrm{L}$ to $2,100 \mu \mathrm{L}$ and neutrophils $-2,300 \mu \mathrm{L}$ to $1,200 \mu \mathrm{L}$ within 7 days. He was then switched from risperidone to olanzapine $10 \mathrm{mg}$ po daily. It was tolerated well, and his WBC and neutrophil count gradually increased; WBC $-2,400 \mu \mathrm{L}$ and neutrophils $-300 \mu \mathrm{L}$ after 7 days. The patient was not experiencing any psychotic symptoms at this time. His depressive symptoms improved, and so he was discharged home. The patient scored 7 on the Naranjo Adverse Drug Reaction Probability Scale, ${ }^{3}$ ie, a probable causation by risperidone.

The patient gave written informed consent for all administered drugs and for the publication of his case.

\section{Discussion}

A literature search was done on PubMed database for available evidence on management of risperidone-induced leukopenia and neutropenia. Review was limited to articles focusing on leukopenia, neutropenia, agranulocytosis, bicytopenia, and underlying pathophysiological mechanisms. The authors manually searched the reference lists of identified papers and other publications by their authors to ensure all articles meeting the criteria were identified. Case reports, case series, and review articles were assessed.

There is anecdotal evidence of leukopenia or neutropenia from risperidone, but there is no evidence-based recommendation for alternate antipsychotic medications. ${ }^{4-15}$ In one case, olanzapine appeared to be hematologically safe in patients who developed blood dyscrasias on clozapine and risperidone. The authors reported a case of a patient with treatment-resistant schizophrenia, who had previously developed leucopenia and neutropenia first on clozapine and subsequently on risperidone. However, when switched to olanzapine, leukocyte and neutrophil began to return to baseline counts. He was thus maintained on it for more than 2 years. ${ }^{9}$

In our case, the patient had been taking risperidone on and off for more than 2 years. His hematological parameters were at baseline during admission in our facility. Restarting risperidone at the lowest recommended dose caused a decline in WBCs and ANC levels. Rechallenging after discontinuation, because of patient preference in the hospital setting, decreased WBCs and ANC. There was subsequent resolution with discontinuation of risperidone and initiation of olanzapine. The patient had no history of HIV/AIDS or any other immunocompromised state, and this was confirmed by Infectious Disease and Hematology teams. He was supported with intravenous antibiotics and recombinant human granulocyte-colony stimulating factor during the inpatient stay for neutropenic fever. Our case adds to the available evidence that leukopenia/ neutropenia induced by risperidone and olanzapine could be due to different pathophysiological mechanisms.

Currently, there is not enough evidence to identify a tangible mechanism of action of risperidone's effect on different blood cells. Existing studies have proposed different mechanisms in different antipsychotics. For example, a recent study by Chen et $\mathrm{al}^{16}$ showed that risperidone, but not haloperidol, has been shown to affect the immune functions of mature Dendritic Cells. Risperidone-treated mature dendritic cell has been shown to produce TNF- $\alpha$, which has the potential to cause death of neutrophils. No studies are available at this time comparing risperidone with olanzapine dendritic cell. Nooijen et $\mathrm{al}^{17}$ attributed toxicity of clozapine to the direct toxic effect of the drug on bone marrow or increased peripheral destruction. Husain et $\mathrm{al}^{18}$ proposed oxidative stress-induced apoptotic changes in granulocytes as a possible mechanism of drug toxicity in patients with clozapine, while Konakanchi et al ${ }^{19}$ postulated that olanzapine being structurally similar to clozapine gives rise to an intermediate toxic metabolite, nitrenium ion, which irreversibly binds to the calls, causing neutropenia.

Toxic metabolites were proposed for risperidone-induced blood dyscrasias, similar to olanzapine and clozapine, but the mechanism appears to be different from olanzapine and is as yet unclear. Effects of lactational exposure of olanzapine and risperidone on the hematology of mice neonates have shown distinct abnormalities in both medications. Bone marrow differential leukocyte count also revealed a dose-dependent decrease of the neutrophil percentage on olanzapine exposure, but not in the risperidone-exposed group. ${ }^{20}$ 


\section{Conclusion}

Based on the above evidence, olanzapine seems to be safe in risperidone-induced reversible leukopenia/neutropenia. As highlighted in our case, risperidone-induced neutropenia could occur during restarting the medication even at a lower dose. For these reasons, we suggest careful monitoring of WBC count in patients on risperidone. We recommend continued research in this domain for evidence-based management of antipsychotic-induced blood dyscrasias.

\section{Disclosure}

The authors report no conflicts of interests in this work.

\section{References}

1. Manfredi G, Solfanelli A, Dimitri G, et al. Risperidone-induced leukopenia: a case report and brief review of literature. Gen Hosp Psychiatry. 2013;35(1):102.e3-102.e6.

2. Oyesanmi O, Kunkel EJ, Monti DA, Field HL. Hematologic side effects of psychotropics. Psychosomatics. 1999;40(5):414-421.

3. Naranjo CA, Busto U, Sellers EM, et al. A method for estimating the probability of adverse drug reactions. Clin Pharmacol Ther. 1981; 30(2):239-245.

4. Shah K, Rizvi M. Bicytopenia: adverse effect of risperidone. Current Psychiatry. 2014;13(4):E1.

5. Meylan C, Bondolfi G, Aubert AC, Baumann P. Reversible neutropenia during a cold: possible involvement of risperidone? A case report. Eur Neuropsychopharmacol. 1995;5(1):1-2.

6. Bondolfi G, Morena P, Dascal DR, Bertschy G. Risperidone and reversible neutropenia: a negative rechallenge. Eur Neuropsychopharmacol. 1996;6(3):257.

7. Godleski LS, Sernyak MJ. Agranulocytosis after addition of risperidone to clozapine treatment. Am J Psychiatry. 1996;153(5):735-736.

8. Dernovsek Z, Tavcar R. Risperidone-induced leucopenia and neutropenia. Br J Psychiatry. 1997;171:393-394.
9. Dernovsek MZ, Tavcar R. Olanzapine appears haematologically safe in patients who developed blood dyscrasia on clozapine and risperidone. Int Clin Psychopharmacol. 2000;15(4):237-238.

10. Finkel B, Lerner AG, Oyffe I, Sigal M. Risperidone-associated agranulocytosis. Am J Psychiatry. 1998;155(6):855-856.

11. Etain B, Roubaud L, Le Heuzey MF, Mouren Simeoni MC. Un cas de leucopénie sous traitement par rispéridone chez un adolescent [A case of leukopenia in treatment with risperidone in an adolescent]. Encéphale. 2000;26(5):81-84. French.

12. Biswas A, Mittal P, Chaturvedi S, Prasad A. Risperidone induced cytopenias. J Assoc Physicians India. 2000;48(11):1122-1123.

13. Sluys M, Güzelcan Y, Casteelen G, de Haan L. Risperidone-induced leucopenia and neutropenia: a case report. Eur Psychiatry. 2004;19(2):117.

14. López Altimiras FX, Muñoz Rodríguez FJ, Escoté Llobet S. Leucopenia asociada al uso de risperidona: presentación de un caso y revisión de la literatura [Leukopenia associated with the use of risperidone: a case report and review of the literature]. Rev Clin Esp. 2006;206(3):162-163. Spanish.

15. Uzun S, Kozumplik O, Jakovljević M, Folnegović-Smalc V. Leukopenia during therapy with risperidone long-acting injectable: two case reports. J Clin Psychopharmacol. 2008;28(6):713-714.

16. Chen ML, Tsai TC, Wang LK, et al. Risperidone modulates the cytokine and chemokine release of dendritic cells and induces TNF$\alpha$-directed cell apoptosis in neutrophils. Int Immunopharmacol. 2012;12(1):197-204.

17. Nooijen PM, Carvalho F, Flanagan RJ. Haematological toxicity of clozapine and some other drugs used in psychiatry. Hum Psychopharmacol. 2011;26(2):112-119.

18. Husain Z, Almeciga I, Delgado JC, et al. Increased FasL expression correlates with apoptotic changes in granulocytes cultured with oxidized clozapine. Toxicol Appl Pharmacol. 2006;214(3):326-334.

19. Konakanchi R, Grace JJ, Szarowicz R, et al. Olanzapine prolongation of granulocytopenia after clozapine discontinuation. $J$ Clin Psychopharmacol. 2000;20(6):703-704.

20. Mishra AC, Mohanty B. Effects of lactational exposure of olanzapine and risperidone on hematology and lymphoid organs histopathology: a comparative study in mice neonates. Eur J Pharmacol. 2010;634(1-3): 170-177.
Neuropsychiatric Disease and Treatment

\section{Publish your work in this journal}

Neuropsychiatric Disease and Treatment is an international, peerreviewed journal of clinical therapeutics and pharmacology focusing on concise rapid reporting of clinical or pre-clinical studies on a range of neuropsychiatric and neurological disorders. This journal is indexed on PubMed Central, the 'PsycINFO' database and CAS,

\section{Dovepress}

and is the official journal of The International Neuropsychiatric Association (INA). The manuscript management system is completely online and includes a very quick and fair peer-review system, which is all easy to use. Visit http://www.dovepress.com/testimonials.php to read real quotes from published authors. 